\title{
Estudo de caso sobre as faltas dos usuários às consultas programadas de uma equipe de saúde da familia no munieipio do Rio de Janeiro
}

\author{
Case study on the faults of seheduled consultation to users of a family health team in the \\ City of Rio de Janeiro
}

\author{
Maria Aliee Pessanha de Carvalho ${ }^{1}$ \\ Camille Melo Barreto e Sousa ${ }^{2}$ \\ Ivo Aurélio Lima Júnior ${ }^{3}$ \\ Marina Fernandes do Prado 4 \\ Rebera Nascimento Marinho da Silva 5
}

\begin{abstract}
Resumo
O excesso de faltas às consultas programadas na Atenção Primária à Saúde no Brasil produz o aumento na fila de espera e também da demanda por urgência. O objetivo da pesquisa foi analisar os motivos relacionados à acessibilidade, que influenciaram as faltas dos usuários às consultas programadas de uma equipe de Saúde da Família. Foi realizado um estudo de caso exploratório, utilizando como técnica a observação participante, análise documental e entrevistas não estruturadas. A categorização da análise de conteúdo temática foi baseada em quatro dimensões da acessibilidade: geográfica, organizacional, sociocultural e econômica. Os resultados encontrados apontaram que nas quatro dimensões analisadas surgiram dificuldades e facilidades à acessibilidade dos usuários aos serviços de saúde.Os problemas de acessibilidade podem decorrer da combinação da ausência de espaços de escuta por parte do serviço com a rigidez programática na organização da agenda dos profissionais da equipe e das diferentes percepções sobre tempo gasto e distância percebida pelos usários. Pôde-se concluir que a compreensão de muitos fenômenos que ocorrem na relação entre profissional $e$ usuário exige disponibilidade para o diálogo. Espaços de discussão com a população poderiam amenizar os efeitos de julgamentos a priori.
\end{abstract}

\section{Abstraet}

Excessive absences to scheduled in Primary Health Care in Brazil consultations has increased in the queue and also the demand for urgency. The objective of the research was to analyze the reasons related to accessibility, which influenced the misconduct of users to scheduled a team of Family Health consultations. An exploratory case study of using art as participant observation, document analysis and unstructured interviews were conducted. The categorization of the thematic content analysis was based on four dimensions of accessibility: geographic, organizational, socio-cultural and economic. The results indicate that the four dimensions analyzed appeared difficult and easy accessibility of users to health services. Accessibility problems can arise from the combination of lack of spaces for listening by the service to program stiffness in the organization of the professional team and the different perceptions of time spent by users to see distance and perceived agenda. It was concluded that the understanding of many phenomena that occur in the relationship between professional and user demands readiness for dialogue. Opportunities for discussion with the population could mitigate the effects of a priori judgments.
Deseritores: Faltas às consultas, Acessihilidade, Acesso, Atenção Primária à Saúde, Estratégia de Saúde da Familia.

Keywords:Missed appointments, Aceessibility, Aceess, Primary Care, Family Health Strategy.

\footnotetext{
1 Pesquisadora da Eseola Naeional de Saúde Públiea Sérgio Aroutea/ FIOGRIZ.

${ }^{2}$ Especialista em Saúde da Familia e Mestranda em Saúde Públiea da Eseola Naeional de Saúde Pública/ FIOCRUZ.

${ }^{3}$ Especialista em Saúde da Familia e Mestrando em Saúde Públiea da Eseola Nacional de Saúde Pública/FIOCRUZ.

${ }^{4}$ Especialista em Saúde da Familia e Mestranda em Saúde Públiea da Eseola Naeional de Saúde Pública/FIOCRUZ.

5 Especialista em Saúde da Familia e Mestranda em Saúde Públiea da Eseola Nacional de Saúde Píblica/FIOCRUZ.
}

Para correspondência:

Ivo Aurélio Lima Júnior

E-mail:ivolima1@gmail.com
Data da Submissão:09/06/2014 Data do Aceite: 08/06/2014 


\section{Introdução}

O Programa de Saúde da Família surgiu em 1994. Ao longo do tempo, ganhou maior visibilidade na medida em que conseguiu oportunizar uma melhora nos índices de qualidade de vida de muitos territórios pobres e com baixa estrutura de serviços de saúde, com a incumbência de propor uma nova concepção para o acesso e a assistência em saúde.

Em 2002, foi estruturada e reconhecida como estratégia, tornando-se o modelo preferencial para a organização da Atenção Primária em Saúde (APS). No Brasil, a Atenção Primária abrange a promoção e a proteção da saúde, a prevenção de agravos, o diagnóstico, o tratamento, a reabilitação, redução de danos e a manutenção da saúde com vistas à atenção integral com impacto na situação de saúde e autonomia dos sujeitos e nos determinantes e condicionantes de saúde.

A Estratégia de Saúde da Família (ESF) é a principal porta de entrada do sistema local de saúde, sendo desenvolvida por meio do exercício de práticas de cuidado e gestão democráticas e participativas, sob a forma de trabalho em equipe, dirigido às populações de territórios definidos, pelas quais assume a responsabilidade sanitária. Utiliza tecnologias de cuidado complexas e variadas que devem auxiliar no manejo das demandas e necessidades de saúde de maior frequência e relevância em seu território, observando critérios de risco, vulnerabilidade, resiliência e o imperativo ético de que toda demanda, necessidade de saúde ou sofrimento deve ser acolhida ${ }^{2}$.

Existem unidades de saúde no país que convivem com modelos de atenção primária distintos, o que caracteriza duplicidade da porta de entrada para os usuários. Exemplos disso são unidades onde o ambulatório médico de especialidades está estruturado nos moldes tradicionais, com formação de filas e distribuição de senhas por ordem de chegada e, a outra porta de entrada, da ESF, organizada por equipes de referência que realizam o acolhimento, obedecendo ao horário marcado e à escala de risco.

Com o avanço da cobertura da ESF no município do Rio de Janeiro, pode-se esperar o aumento por demanda assistencial. O trabalho territorializado da ESF implica em uma busca ativa, no território, por fatores que possam interferir direta ou indiretamente na saúde das famílias pelas quais são responsáveis.

Diretamente ligada à demanda, está a oferta de serviços disponibilizados a população. É sabido que a demanda por serviços assistenciais de saúde é maior que a capacidade do Sistema Único de Saúde (SUS) em provê-los, isto é, a demanda é maior do que a oferta. Essa situação produz imensas filas de espera e consequentemente, a piora da situação de saúde da população.

O fato de o usuário estar cadastrado por uma equipe de Saúde da Família, não garante o acesso. A situação se torna mais complexa caso a concepção de acesso em questão não seja apenas "o uso ou não dos serviços de saúde" e tão pouco a simples entrada do usuário nesses serviços.

Acesso é um conceito muito importante em políticas de saúde e um dos termos mais frequentemente utilizados em discussões sobre o sistema de saúde. Apesar disso, não é muito bem definido e muitas vezes é utilizado como sinônimo de outros conceitos também mal definidos.

Travassos e Martins realizaram uma revisão dos vários sentidos do conceito de acesso, afirmando que muitas vezes o termo é utilizado de forma "[...] imprecisa, e pouco clara na sua relação com o uso de serviços de saúde. É um conceito que varia entre os autores e que muda ao longo do tempo e de acordo com o contexto" (p.191).

Nesta pesquisa foi considerado o conceito de acessibilidade de Donabedian e para operacionalizar a análise dos motivos que levaram às faltas dos usuários às consultas programadas, utilizaram-se as quatro dimensões propostas por Fekete para avaliar a acessibilidade dos serviços de saúde: geográfica, organizacional, sociocultural e econômica.

Após estudo bibliográfico, percebeu-se que é reduzida a produção bibliográfica sobre o tema das faltas dos usuários às consultas programadas na APS. Porém, é possível encontrar várias notícias, por meio eletrônico, que mencionam o grande percentual de faltas em diferentes municípios, considerando os três níveis de atenção. É importante ressaltar a ausência de informações oficiais, em relação a esta questão, no município do Rio de Janeiro.

Durante a fase exploratória deste estudo foi realizado um levantamento no Centro Municipal de Saúde (CMS) pesquisado. 
Constatou-se que aproximadamente $32 \%$ dos usuários agendados, para médicos e enfermeiros das quatro equipes de Saúde da Família, não compareceram às consultas entre os meses de maio a junho de 2012. Os relatos dos profissionais reforçam a presença do problema e suas repercussões para o funcionamento do serviço de saúde supracitado.

$\mathrm{O}$ excesso de faltas às consultas programadas na atenção básica expressa 0 desperdício de recursos, a falta de continuidade do cuidado, o prejuízo na organização do processo de trabalho da equipe, bem como o aumento na fila de espera e na demanda por urgência e emergência.

Ao considerar a importância desses acontecimentos e a pouca bibliografia sobre o tema, este estudo pode contribuir para melhor compreensão do fenômeno das faltas, otimizando os recursos oferecidos à comunidade e sua adequação às necessidades dos usuários deste território.

Deste modo, o objetivo do estudo foi analisar os motivos relacionados à acessibilidade que influenciaram as faltas dos usuários às consultas programadas de uma equipe de Saúde da Família, na perspectiva dos usuários e dos profissionais de saúde que compõe a equipe, no município do Rio de Janeiro. Uma vez identificadas estas barreiras impostas aos usuários, ainda que não removidas, poderão ser atenuadas para melhor utilização dos recursos e da oferta dos serviços de saúde.

\section{Metodologia}

Trata-se de um estudo de caso exploratório de natureza qualitativa, pois remete a uma investigação empírica que pretende averiguar um fenômeno contemporâneo em profundidade e em seu contexto de vida real. Além disso, a pesquisa exploratória visa proporcionar maior familiaridade com $\mathrm{o}$ problema.

Esta pesquisa é fruto do trabalho de conclusão de curso de Residência Multiprofissional em Saúde da Família da Escola Nacional de Saúde Pública Sergio Arouca, realizada pelos residentes lotados em um CMS do município do Rio de Janeiro. Essa unidade de saúde integra no mesmo serviço quatro equipes da ESF e profissionais vinculados ao modelo de atenção ambulatorial tradicional. $\mathrm{O}$ território de abrangência do ambulatório compreende um total de 51.485 indivíduos, e as equipes de Saúde da Família são responsáveis por $20 \%$ destes, segundo os dados obtidos do Relatório de Gestão da unidade de saúde do ano de 2012. A população coberta pela ESF é em sua maioria moradora das comunidades próximas. A Estratégia de Saúde da Família teve início nesta unidade em outubro de 2010, fazendo parte da proposta de expansão de cobertura à população do Rio de Janeiro.

Os sujeitos dessa pesquisa foram $o$ médico, enfermeiro, técnico de enfermagem e Agentes Comunitários de Saúde - de uma das equipes do CMS e os usuários cadastrados pela equipe que faltaram às consultas programadas médicas e de enfermagem, no período entre outubro a dezembro de 2012.

A escolha por esta equipe se deu pelo fato da mesma ter apresentado a questão das faltas como um problema para seu trabalho e ser a única equipe completa no período de realização desta pesquisa.

Todos os entrevistados foram esclarecidos quanto aos objetivos, riscos e benefícios desta pesquisa, por meio do Termo de Consentimento Livre e Esclarecido (TCLE), de acordo com a resolução ${ }^{\circ}$ 196/96. Esse trabalho foi submetido ao Comitê de Ética em Pesquisa (CEP) da Escola Nacional de Saúde Pública Sérgio Arouca, parecer $\mathrm{n}^{\mathrm{o}}$ 08303412.8.0000.5240. A pesquisa visou somente à verificação de dados encontrados em documentos da equipe e a obtenção de novos dados através de entrevistas individuais.

As técnicas de pesquisa utilizadas foram: entrevista semiestruturada, observação participante ${ }^{11}$, análise documental das agendas de atendimentos do médico e do enfermeiro, diagnóstico situacional do CMS e fluxograma descritor da demanda programada da unidade de saúde.

Os dados coletados das entrevistas foram analisados segundo a perspectiva da Análise de Conteúdo Temática, que consiste na elaboração de categorias, visando à obtenção, por procedimentos sistemáticos e objetivos, de indicadores que permitam a inferência de conhecimentos relativos às condições de produção/recepção destas mensagens.

Elaboraram-se categorias de análise com vistas à obtenção de indicadores a partir das quatro dimensões da acessibilidade de Fekete ${ }^{6}$ : geográfica, econômica, organizacional e sociocultural (Quadro 1). 


\begin{tabular}{|l|l|}
\hline $\begin{array}{l}\text { Dimensão } \\
\text { Geográfica }\end{array}$ & $\begin{array}{l}\text { Proximidade do serviço como fator de } \\
\text { escolha na rede; Percepção da distância; } \\
\text { Percepção do tempo gasto; Fatores } \\
\text { climáticos. }\end{array}$ \\
\hline $\begin{array}{l}\text { Dimensão } \\
\text { Organizacional }\end{array}$ & $\begin{array}{l}\text { Coexistência de modelos de atenção e } \\
\text { dupla porta de entrada; Tempo real de } \\
\text { espera; Formas de agendamento; Turnos } \\
\text { de funcionamento; Processos de } \\
\text { trabalho; Organização da agenda; } \\
\text { Condutas da equipe; Continuidade/ } \\
\text { longitudinalidade do cuidado. }\end{array}$ \\
\hline $\begin{array}{l}\text { Dimensão } \\
\text { Sociocultural }\end{array}$ & $\begin{array}{l}\text { Percepção sobre o corpo e a doença; } \\
\text { Crenças relativas à saúde; Credibilidade } \\
\text { nos serviços de saúde; Diferenças } \\
\text { socioculturais entre profissionais de } \\
\text { saúde e os usuários do serviço; Crenças } \\
\text { e hábitos quanto aos cuidados com a } \\
\text { saúde. }\end{array}$ \\
\hline $\begin{array}{l}\text { Deslocamento dos usuários no território; } \\
\text { Obtenção de medicamentos e materiais } \\
\text { de consumo; } \\
\text { Econonônãos }\end{array}$ \\
\hline
\end{tabular}

Quadro 1. Indicadores segundo as quatro dimensões de acessibilidade.

Fonte: Elaboração própria, adaptado de Fekete ${ }^{6}$.

\section{Resultados}

Os achados da pesquisa foram categorizados a partir das quatro dimensões de acessibilidade descritas no Quadro 2. Cada dimensão dispõe de um conjunto de subcategorias com base nos indicadores utilizados na pesquisa.

\section{Dimensão Geográfica}

A dimensão geográfica foi dividida em quatro subcategorias de análise: proximidade do serviço como fator de escolha na rede (preferir ESF a outro serviço), percepção da distância, percepção do tempo e referência aos fatores climáticos.

Como forma de contextualizar as falas dos entrevistados, foi importante descrever as características geográficas do território de abrangência da equipe de SF escolhida. A área em que foi realizado o presente estudo é caracterizada por ladeiras íngremes, becos, ruas não asfaltadas e sem calçadas, lixo desprezado em locais inadequados, local de comércio de drogas (poder paralelo) e uma praça. Essas características aparecem com frequência nas periferias e podem ser considerados obstáculos ao deslocamento das pessoas até o serviço de saúde. Além desses aspectos, a rua onde está o CMS estudado é dividida por um córrego, o qual pode transbordar em dias de chuva intensa.

\section{Proximidade do serviço como fator de eseolha na rede}

Foi possível observar que a proximidade do CMS com o domicílio dos entrevistados é um critério de escolha para a utilização do mesmo. Entretanto, foram relatadas algumas dificuldades

\begin{tabular}{|c|c|}
\hline $\begin{array}{l}\text { Dimensão } \\
\text { geográfica }\end{array}$ & $\begin{array}{l}\text { Refere-se aos aspectos físicos do território } \\
\text { (rios, grandes avenidas, morros etc.) e à } \\
\text { distância entre a população e os serviços de } \\
\text { saúde. "(...) deve ser medida em função do } \\
\text { tempo que, pelos meios habituais de } \\
\text { transporte, se consome para obter } \\
\text { assistência à saúde" (Fekete }{ }^{6}, \text { p.117). }\end{array}$ \\
\hline $\begin{array}{l}\text { Dimensão } \\
\text { organizacional }\end{array}$ & $\begin{array}{l}\text { "(...) está representada pelos obstáculos que } \\
\text { se originam nos modos de organização dos } \\
\text { recursos de assistência à saúde. (...)" } \\
\text { (Fekete }, \text { p.118). Esses obstáculos podem ser } \\
\text { definidos como: a) internos (demora na } \\
\text { obtenção da consulta, tipo de marcação de } \\
\text { horário, turnos de funcionamento, etc.); b) } \\
\text { externos (demora na espera pelo } \\
\text { atendimento do médico na própria unidade } \\
\text { de saúde e para fazer exames laboratoriais). }\end{array}$ \\
\hline $\begin{array}{l}\text { Dimensão } \\
\text { sociocultural }\end{array}$ & $\begin{array}{l}\text { Refere-se à apreciação dos fenômenos que } \\
\text { determinam a busca do serviço de saúde. } \\
\text { Na perspectiva da população: a percepção } \\
\text { que o indivíduo tem da gravidade de sua } \\
\text { doença, etiologia, tipo de tratamento e nível } \\
\text { de conhecimento sobre a oferta de serviços } \\
\text { de saúde; medo do diagnóstico e das } \\
\text { intervenções dele decorrentes; crenças e } \\
\text { hábitos quanto aos cuidados com a saúde e } \\
\text { vergonha no caso de doenças sexualmente } \\
\text { transmissíveis ou estigmatizastes. Na } \\
\text { perspectiva do sistema de saúde: a } \\
\text { formação de profissionais de saúde } \\
\text { desvinculada da realidade das condições de } \\
\text { vida e saúde da população; a falta de } \\
\text { preparo das equipes de saúde e das } \\
\text { instituições frente à diversidade de } \\
\text { pacientes com distintas características } \\
\text { socioculturais e incipiência dos processos de } \\
\text { participação dos usuários nas organizações } \\
\text { dos serviços. }\end{array}$ \\
\hline $\begin{array}{l}\text { Dimensão } \\
\text { econômica }\end{array}$ & $\begin{array}{l}\text { Está relaciona às despesas das famílias com } \\
\text { serviços de saúde, incluindo o consumo de } \\
\text { tempo, energia e recursos financeiros para } \\
\text { busca e obtenção da assistência, prejuízos } \\
\text { por perda de dias de trabalho, possíveis } \\
\text { perdas decorrentes de afastamento por } \\
\text { doença; custo do tratamento } \\
\text { (medicamento). }\end{array}$ \\
\hline
\end{tabular}

Quadro 2. Definição das quatro dimensões de acessibilidade.

Fonte: Elaboração própria, adaptado de Fekete ${ }^{6}$.

no trajeto relacionadas ao deslocamento com crianças de colo, ausência de calçadas para os pedestres, locomoção com carrinho de criança e o fato do posto de saúde ser longe dos outros 
equipamentos sociais, como a escola, o que dificulta aos responsáveis conciliar a rotina com os filhos e a ida para a consulta.

"A dificuldade é a locomoção mesmo, porque é difícil levar ela. Eu tenho um probleminha no braço, que é quebrado, ai eu tenho que carregar o carrinho e ela. Eu tenho que escolher como poder correr com ele lá embaixo. Pra subir de novo é difícil. Mas eu prefiro levar ela no braço, porque se eu for me locomover com o carrinho, eu tenho que levar o carrinho e ela" (E03).

\section{Percep̣̂̃o da distâneia}

A percepção da distância diferiu consideravelmente entre os entrevistados que residem em regiões próximas na comunidade. A diferença de idade não surgiu como um fator contribuinte para a discrepância entre os relatos. Por exemplo, dois usuários do mesmo sexo, com idade de 25 e 76 anos, tiveram a mesma percepção em relação a essa categoria.

O meio de transporte mais utilizado foi a "Kombi" (transporte alternativo), pois ela chega até o início da comunidade, deixando o usuário mais próximo de sua residência. Outros meios de locomoção também surgiram nas falas dos entrevistados, como ônibus que oferecem carona ou o uso do automóvel particular, este com menos frequência. A caminhada também é bastante utilizada como meio de acesso ao serviço.

"Não vou a pé nem daqui até a igreja, porque a perna dói demais. Se tiver carro aqui, vou de carro, se não tiver, pego a Kombi" (E09).

"Eu vou a pé. Porque assim eu vou até o ponto final do ônibus aqui na parte de cima, porque eles dão carona para os moradores até na praça" (E04).

\section{Pereepeão do tempo gasto}

A terceira subcategoria de análise é a percepção do tempo que o usuário tem do deslocamento de sua residência até o serviço de saúde pesquisado. Diferentes respostas foram encontradas considerando distâncias similares. Esse fato pode ser explicado pela diferença de idade entre os entrevistados, a dificuldade de locomoção por problemas físicos ou quando o usuário está em companhia de uma criança, como podemos observar na fala a seguir.

"Acho que uns quatro minutos, né?" (E10).
"Até a unidade, levo uns 30 minutos. Se for a pé legal, uns 40 minutos, porque os dois andando (ela e o filho), né, demora mais. Mas ai, como eu pego essa carona, vou de ônibus até a praça, mas ali tem um tempo de esperar, o onibus vim pra aparecer aqui pra depois pegar esta caroninha. Aí vale a pena às vezes ir a pé" (E04).

\section{Fatores climáticos}

Esta categoria analisa os fatores climáticos e sua interferência no deslocamento da população até o serviço de saúde. Apenas três entrevistados fizeram menção a essa categoria, sendo um profissional e dois usuários. É possível que para os entrevistados os fatores do clima não interfiram tanto no deslocamento quando comparados à percepção do tempo ou da distância.

\section{Dimensão Organizacional}

Segundo Fekete (1996), a acessibilidade organizacional é representada pelos obstáculos originários dos modos de organização dos recursos de assistência à saúde. Tais obstáculos podem se encontrar na porta de entrada da unidade, nas características internas ou na continuidade do cuidado.

Essa dimensão foi dividida em três subcategorias de análise: porta de entrada, características internas do serviço de saúde e continuidade/longitudinalidade do cuidado (Quadro 3). A forma como está organizado o serviço a partir desses três eixos pode se constituir como obstáculo.

\begin{tabular}{|l|l|}
\hline \multicolumn{1}{|c|}{ Subcategorias } & \multicolumn{1}{|c|}{ Características } \\
\hline Porta de entrada & $\begin{array}{l}\text { Coexistência de modelos de atenção e } \\
\text { dupla porta de entrada, tempo real de } \\
\text { espera (tempo entre o agendamento e data } \\
\text { da consulta), formas de agendamento e } \\
\text { turnos de funcionamento. }\end{array}$ \\
\hline $\begin{array}{l}\text { Características } \\
\text { internas }\end{array}$ & $\begin{array}{l}\text { Acolhimento e processos de trabalho, } \\
\text { agenda, organização da demanda } \\
\text { programada. }\end{array}$ \\
\hline $\begin{array}{l}\text { Continuidade do } \\
\text { cuidado }\end{array}$ & $\begin{array}{l}\text { Situações em que o usuário necessita de } \\
\text { acompanhamento regular. }\end{array}$ \\
\hline
\end{tabular}

Quadro 3. Subcategorias da Dimensão Organizacional da Acessibilidade.

Fonte: Elaboração própria, 2013. 


\section{Porta de entrada}

Na unidade de saúde em questão convivem dois modelos de APS com características distintas no que diz respeito à porta de entrada. Trata-se de uma unidade mista, onde somente parte do território é coberto pela ESF, sendo $\mathrm{o}$ restante dele responsabilidade da Unidade Básica de Saúde que atua numa perspectiva mais seletiva, individualizada e com a incorporação de algumas especialidades médicas tais como ginecologia e pediatria.

\begin{abstract}
"Eu só achei ruim porque eu fui lá, enfrentei fila, depois eu vi que tava demorando aí eu perguntei lá pro guardinha. [...]"Fulano, o médico fulano de tal vai vir hoje? "Não, não vai vir, não" (E02).
\end{abstract}

$\mathrm{O}$ relato de E02 evidencia a dificuldade enfrentada pelos usuários com relação a esta duplicidade na porta de entrada da unidade. Um problema que pode ser potencializado pela ambiguidade de critérios que definem os usuários de cada serviço.

Os entrevistados também se referiram à utilização de critérios distintos para o agendamento de consultas que resultam em diferentes tempos de espera, de acordo com as condições de risco e vulnerabilidade. Porém, esta conduta nem sempre é compreendida pelos usuários.

Outro aspecto relevante para o aumento do tempo de espera foi a existência de equipes incompletas (sem médico ou enfermeiro) e o acúmulo de funções por parte destes (responsabilidade técnica e regulação) que contribuíram para a redução de turnos de atendimento.

Os turnos de funcionamento do CMS foram apontados pelos entrevistados como um obstáculo ao comparecimento à consulta, apesar de funcionar em horário ampliado $(7 \mathrm{~h}-19 \mathrm{~h})$.

"Toda vez que, eu estava trabalhando fora, o horário não dava para ir" (E17).

\section{Caracteristieas internas do serviço de saúde}

A referência à demanda espontânea como dificuldade para organização do processo de trabalho apareceu com frequência nas falas dos profissionais da equipe.

\begin{abstract}
"Às vezes, tem criança, adulto, onde o usuário aparece e a gente tem que atender porque às vezes é uma falta de receita, a pressão tá lá no alto, a pessoa tá passando mal. Então, isso atrapalha um pouco a agenda da médica, da enfermeira não.A enfermeira o Acolhimento não atrapalha tanto como a agenda da médica" (P02).
\end{abstract}

A rigidez programática para organização da agenda da equipe de Saúde da Família associada ao excessivo controle externo do trabalho dos profissionais (gestão por resultados ou metas) também pode produzir barreiras à acessibilidade, apesar de não terem sido percebidos entre os profissionais como tal.

\begin{abstract}
"Dias específicos para cada grupo, mais demanda espontânea. Segunda-feira é folga, terça-feira pela manhã, pré-natal e a tarde também; quarta pela manhã, puericultura e na parte da tarde saúde da mulher, para preventivo e entrega de resultado e orientações; quinta-feira de manhã, visita domiciliar, a tarde reunião de equipe; na sexta-feira de manhã, hiperdia e a cada 15 dias na parte da tarde, planejamento familiar e outros 15 dias, hiperdia novamente, hipertensos e diabéticos" (P03).
\end{abstract}

Não houve consenso entre os componentes da equipe sobre quais seriam as condutas mais adequadas para lidar com o problema das faltas. Todavia, é um movimento destes, quando possível, facilitar a remarcação para os usuários faltosos segundo critérios subjetivos.

Além disso, a maneira como está organizado o trabalho da equipe não foi apontada por nenhum dos seus componentes como uma possível barreira à acessibilidade dos usuários do serviço de saúde, o que pode ser consequência da dificuldade de produzir reflexões e análises sobre o processo de trabalho.

Atualmente, o único espaço instituído para realização destas reflexões e análises é o da reunião de equipe, que dificilmente pode contar com a participação de todos os profissionais, ora atribulados por outras atividades, ora desmotivados para participar das reuniões.

\section{Continuidade / Iongitudinalidade do eviidado}

O não atendimento de algumas demandas pode fragilizar a legitimidade do modelo assistencial, o vínculo, a longitudinalidade do cuidado prestado e comprometer o projeto 
terapêutico formulado submetendo o usuário a riscos. É o que reflete o relato de E15:

\begin{abstract}
"Aí eu vinha aí, perguntei a moça se não era fácil pegar uma receita, ela disse: - Aqui não tem ninguém pra dar receita pra senhora. [...] Eu falei: - E agora? Eu tenho que viajar... Como é que eu vou viajar sem remédio? [...]Aí cheguei na Bahia, eu tenho um irmão lá. Aí meu irmão, lá tem aquelas farmácia dos trabalhador...Ela vende sem receita, né? [...]Aí eu ainda até comprei lá. Trinta e seis...Porque o remédio acabou o quanto eu tinha levado daqui, tinha acabado. Aí eu falei: E agora? Eu não posso ficar sem remédio porque eu tenho medo,porque[...]vez em quando, eu tenho uns negócio cair na... Eu caio, eu... Agora tá me dando umas tonteira" (E15).
\end{abstract}

\section{Dimensão Sociocultural}

A dimensão sociocultural compreende um conjunto de fatores referentes às características individuais dos usuários e o contexto no qual estão inseridos $\mathrm{e}$, as características do serviço e dos profissionais de saúde, as quais podem se tornar obstáculos à acessibilidade $^{5}$. Essa dimensão foi subdividida em três categorias: perfil profissional da equipe; $\mathrm{o}$ olhar da equipe e o olhar dos usuários.

\section{O perfil profissional da equipe}

No que se refere à qualificação dos profissionais da equipe $\mathrm{W}$, de modo geral, podese afirmar que eles não têm formação e experiência para atuar na ESF, com exceção da dentista, que trabalha junto a equipes de Saúde da Família há mais de cinco anos. A médica embora tenha tido longa experiência em atenção básica, esta foi desenvolvida no modelo de atenção tradicional ambulatorial.

Os ACS e todo restante da equipe contaram com apenas um curso introdutório de uma semana, no início da ESF na unidade, como ferramenta de qualificação para atuarem nessa lógica de atenção.

\section{O olhar da equipe}

Um dos questionamentos feito à equipe $\mathrm{W}$ diz respeito a sua opinião sobre os motivos das faltas dos usuários às consultas programadas. A maioria dos profissionais considerou o "descaso, desinteresse" do usuário pelo serviço oferecido ou a "facilidade da remarcação" como principais motivos das faltas. A ausência do cuidado preventivo também foi apontada como motivo para as faltas.

"Bom existem vários motivos. Para mim, principais motivos são, em primeiro lugar, a facilidade que eles têm de vir depois. Então, às vezes, a pessoa falta à consulta, mas ela consegue com tanta facilidade vir no outro dia que não tem responsabilidade no dia da consulta. Ou (...) falta de interesse mesmo" (P1).

“(...) mas a minha opinião é que, na verdade, eles são muito descansados, porque é muito fácil." (P2).

Os profissionais de saúde reconhecem as mães das crianças de zero a dois anos, grupo da puericultura, como o grupo mais faltoso. Embora o horário seja visto como um obstáculo para o comparecimento dessa população, nenhuma tentativa de alteração da agenda foi relatada com o objetivo de facilitar a acessibilidade dessa população.

Foi possível observar que a opinião dos profissionais a respeito das faltas dos usuários às consultas é carregada de julgamento moral, sem o real conhecimento sobre a rotina dos usuários.

Quase todos os profissionais concordam com "punições" aos usuários faltosos ou, indiretamente, realizam algum mecanismo punitivo. Embora esse sentimento esteja presente na fala da equipe de modo geral, os entrevistados também relataram tentar "encaixar" esses usuários na agenda. Além disso, os profissionais afirmaram não ter nenhuma conduta padrão nessas situações.

"Eu acho que a gente não deve facilitar na hora
de remarcar. Tem que ser colocado que perdeu
a consulta vai ser remarcado para quando tiver
vaga, e não "deixa que vamos encaixar". É
uma coisa complicada, mas... Ou seja, ele tem
que ser punido pela falta." (P1).

\section{O olhar dos usuários}

A maioria dos entrevistados disse ter vindo deles o interesse em agendar a consulta, seja para os filhos, ou para si mesmo. Eles justificaram, também, a necessidade da consulta pela presença de algum sintoma ou sinal e, 
poucos afirmaram ter marcado a consulta como rotina, pela importância do cuidado.

"Precisava sim, porque "vira e mexe" o tempo
muda, o clima... ela fica gripada" (E03).
"Precisava (...) porque eu tava precisando, tava
passando mal. Pressão alta com mal estar".
(E12)
aos motivos das faltas, os

Quanto aos motivos das faltas, os
entrevistados relataram a priorização de usuários entrevistados relataram a priorização de
outras necessidades; o esquecimento e dificuldade com o horário da consulta como principais motivos.

Por último, vale ressaltar que as condições de vida dos usuários não foram levadas em consideração pelos profissionais como possíveis motivos para as faltas. Observe a seguinte fala:

\begin{abstract}
"Porque a gente às vezes, no verão, a gente fica sem água na encanação, então a gente tem que ir na cisterna reserva, puxar água.. então se naquele dia eu não tiver água reservada no barril, e tiver acabado a água da torneira, eu não vou poder ir. Porque como é que a gente vai lavar a boca, tomar banho, escovar o dente? Não dá né? Aí, quer dizer, já perdeu." (E04).
\end{abstract}

Esse relato é bastante ilustrativo e possibilita o contraponto com a visão dos profissionais sobre os motivos das faltas. Muitas vezes o profissional desconhece o cotidiano da população de seu território. $\mathrm{O}$ abastecimento insuficiente e irregular de água faz parte da realidade dessas pessoas. Causa certo estranhamento o fato dos ACS residirem nesse mesmo território e ainda sim, o desinteresse e o descompromisso foi apontado como os principais motivos das faltas.

\section{Dimensão Eeonômiॄa}

As barreiras de acessibilidade à utilização dos serviços de saúde também podem ser identificadas na dimensão econômica e estão relacionadas às políticas sociais e econômicas e contextualizadas no cenário político nacional e internacional. Remete à reflexão crítica sobre os padrões de gestão das políticas públicas e sua conformação no Brasil.

Na proposta do processo de avaliação dos serviços de saúde no estudo da acessibilidade, Fekete $^{6}$ observou que a oferta insuficiente de ações e serviços faz com que o gasto em saúde das famílias brasileiras ainda seja elevado. A autora incluiu neste gasto "o consumo de tempo, energia e recursos financeiros para busca e obtenção da assistência à saúde, os prejuízos por perda de dias de trabalho, as possíveis perdas decorrentes de afastamento, o custo do tratamento e outros" (p.119).

\section{Deslocamento dos usuários no território}

O estudo da dimensão econômica apontou que, no cenário de pesquisa, alguns elementos foram apontados pelos entrevistados como facilitadores de acessibilidade ao serviço de saúde, como o consumo de tempo e a obtenção de medicamentos e materiais de consumo na unidade de saúde. Outros aspectos, entretanto, foram identificados como barreiras, como o dispêndio de tempo e energia para obtenção da consulta, a falta de medicamento na unidade e as condições socioeconômicas dos usuários.

A percepção doconsumo de tempo foi percebida tanto como uma facilidade quanto uma dificuldade no acesso aos serviços de saúde da referida unidade:

\section{"Eu num acho que demora não, porque [...] eu não tenho esse negócio de ter pressa, eu sô tranquila, sô uma pessoa calma. Eu vejo o povo lá briga por causa de fila, porque não sei o que." (E02).}

$\mathrm{Na}$ opinião dos profissionais entrevistados, o tempo, energia e recursos são desperdiçados em consequência das faltas dos usuários e, de algum modo, se conformam em barreiras na acessibilidade dos usuários. Ou seja, o volume de faltas de usuários às consultas médicas e de enfermagem, exerce um movimento reflexivo com interferência no próprio usuário, configurando um obstáculo no cotidiano destes.

\footnotetext{
"De oito, faltam quatro, três. E atrapalha porque quando tem gente que quer vir marcar alguma coisa grave, acaba que a consulta fica lá na frente, porque tem muita gente marcada e nem todos vem." (P04).
}

\section{Obtenţão de medicamentos e materiais de consumo}

$\mathrm{O}$ acesso aos medicamentos e materiais de consumo na unidade de saúde, realizada pelo setor da farmácia, foi identificada como uma facilidade do serviço. Pois possibilita que o usuário poupe recursos financeiros na obtenção dos medicamentos e materiais necessários ao 
tratamento.

Neste caso, além da economia de recursos, o usuário aproveita melhor o seu tempo e poupa energia quando não se faz mais necessário buscar tais provisões em outros estabelecimentos, por exemplo, a Farmácia Popular, que neste caso está localizada a uma distância aproximada de cinco quilômetros, ou seja, mais de 30 minutos do centro da comunidade, pelos meios convencionais (distância e tempo médio foram calculados a partir de informações do Google Maps (C)).

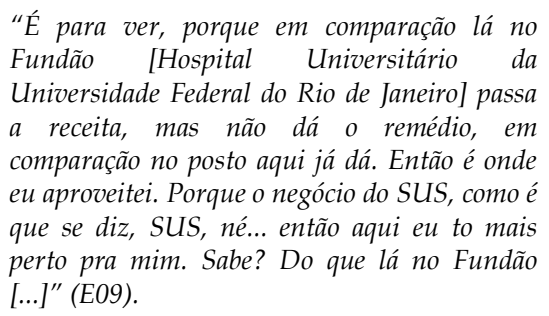

Embora a proximidade e a disponibilidade à dispensação de medicamentos tenha se constituído em uma facilidade, as despesas com medicamentos que deveriam estar disponíveis, mas não estão, foi uma dificuldade relatada por um usuário. Este relato ilustra a condição de injustiça social às quais sujeitos estão submetidos e a privação, cotidiana, do direito de contrair mais esta despesa.

"Precisava [da consulta] porque quando falta o curativo aqui, eu preciso dela para falar com ela, porque ela que passa o curativo e tudo, né?" (E09).

\section{Condições socioeronômißas}

Este estudo constatou, através dos relatos dos profissionais e usuários do serviço, além da observação participante dos pesquisadores, que as condições socioeconômicas impõem limitações à acessibilidade e podem se configurar em barreiras no seu cotidiano na busca pelos serviços de saúde.

\footnotetext{
"Eu vô a pé, porque eu não tenho dinheiro de passagem" (E2)

"Se aparecer alguma faxina, é claro que elas vão priorizar o dinheiro, que a saúde" (P6).
}

Os profissionais entrevistados revelaram o conhecimento que eles têm da realidade de carência e restrição vivida cotidianamente pelos usuários, como também expressou certo distanciamento, talvez pela imobilidade para atuação, diante do cenário das iniquidades:

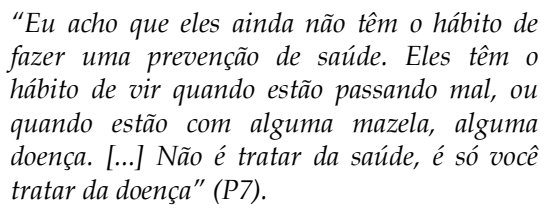
fazer uma prevenção de saúde. Eles têm o hábito de vir quando estão passando mal, ou quando estão com alguma mazela, alguma doença. [...] Não é tratar da saúde, é só você tratar da doença" (P7).

Segundo Feketé, a taxa (nível) de emprego é o indicador mais utilizado para medir acessibilidade na dimensão econômica, baseado nos estudos que têm demonstrado que quanto maiores os níveis de emprego, maior a utilização dos serviços de saúde. Apesar deste dado não ter sido avaliado neste estudo, o trabalho informal foi assinalado, de acordo com os dados das entrevistas, como barreira da acessibilidade aos serviços de saúde:

\section{"Perdi dia [de trabalho], né? Descontaram porque eu não trabalho de carteira assinada. Trabalho em casa de família, mas não é de carteira assinada" (E12).}

\section{Diselssão}

Observou-se nesta pesquisa que os aspectos geográficos tiveram pouca influência nas faltas dos usuários às consultas programadas. A percepção da distância e tempo gasto até a unidade de saúde variou bastante entre os entrevistados, mesmo entre os que utilizam do mesmo meio de transporte. Todavia, esta diferença percebida não estava associada, necessariamente, a alguma limitação física, pois distâncias similares apresentaram diferentes respostas, considerando perfis semelhantes dos usuários.

Alguns entrevistados mencionaram dificuldades em relação "ao caminhar pela comunidade". A falta de infraestrutura urbana nas comunidades do Rio de Janeiro é uma realidade para seus moradores. Segundo o IBGE (Instituto Brasileiro de Geografia e Estatística) censo de 2010- esse município tem a maior população vivendo em aglomerados subnormais do país. São 1.393.314 pessoas nas 74 favelas, ou seja, 22,03\% da população total do Rio de Janeiro.

O crescimento urbano desordenado originou-se a partir da década de 1950, como consequência dos avanços tecnológicos na agricultura e o alto custo de vida no campo. O que contribuiu para a supervalorização dos terrenos nas grandes cidades e o surgimento das periferias 
que não continham infraestrutura básica de serviços oferecidos pelo Estado.

A despeito da distância percorrida até a unidade de saúde não ter sido considerada motivo para as faltas, a unidade de saúde estudada não corresponde aos moldes da PNAB de 2011, que recomenda como distância ideal "para no máximo 12 mil habitantes, localizada dentro do território". A comunidade coberta pela equipe de SF estudada dista, aproximadamente, $1,7 \mathrm{~km}$, o que representa vinte minutos a pé da unidade (distância calculada a partir de informações do Google Maps@), fora da comunidade.

A escolha da unidade de saúde pautada na proximidade é pertinente quando se observa que os idosos, as mulheres e as crianças são os usuários que mais utilizam os serviços da ESF. Pensando neles, o deslocamento deve ser o mais fácil possível, para que este não seja utilizado como argumento para não se vincularem ao serviço e, consequentemente, apresentar-se como barreira de acessibilidade.

Quanto à dimensão organizacional, a evidenciação das barreiras organizacionais à acessibilidade dos usuários aos serviços de saúde permite a reflexão e reformulação da organização do serviço, bem como das práticas desenvolvidas, fazendo com que estas estejam mais próximas das necessidades dos usuários.

Para Cohn et al, é um dado de realidade que a população estrutura as suas estratégias de acesso aos serviços a partir da referência do seu cotidiano e na sua vinculação com as condições mais imediatas de disponibilidades oferecidas, mesmo nas situações que exigem maior complexidade. A acessibilidade da população corresponde à relação funcional entre as "resistências" oferecidas pelos serviços e o "poder de utilização" que se formam através de experiências, percepções e valores.

Algumas dificuldades observadas que podem ter contribuído para o fenômeno das faltas são de ordem estrutural, portanto, extrapolam a capacidade de resolução no âmbito da equipe e, até mesmo da unidade de saúde. Por exemplo, a justaposição de dois modelos de ABS distintos.

É importante considerar que o modo de organização do processo de trabalho dos profissionais, no ponto de vista destes, não foi apontado como um possível obstáculo à acessibilidade dos usuários. Em geral, os motivos das faltas que foram elencados pelos profissionais estão relacionados ao comportamento dos usuários e dificuldades pessoais, não considerando a relação com a organização do serviço.

As poucas estratégias de apoio da gestão municipal às equipes de saúde com vistas às transformações das práticas assistenciais e a opção por mecanismos externos de controle do trabalho (estabelecimento de metas e indicadores de resultado) contribuem para a pouca autonomia das equipes na estruturação de um trabalho mais condizente com as necessidades de saúde do território.

No que tange a formação profissional dos membros da equipe, a falta de formação específica para atuar na atenção básica não contribui para efetivação da mudança do modelo assistencial em saúde. De acordo com Ceccim:

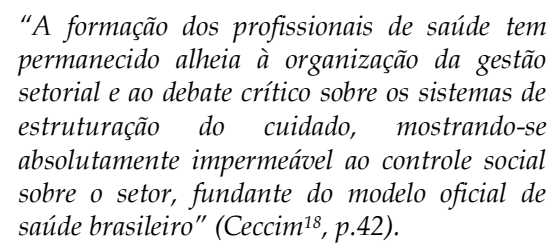

O trabalho na Estratégia de Saúde da Família exige o desenvolvimento de ferramentas ligadas ao campo relacional da assistência, o que Merhy chamou de tecnologias leves. Além do conhecimento técnico e da infraestrutura organizacional, espera-se a construção de vínculo entre usuário e profissional para a construção do cuidado humanizado, estabelecendo uma relação de corresponsabilidade.

Outro aspecto importante percebido no relato dos profissionais e usuários faltosos foi a menor preocupação com o cuidado preventivo à saúde. O longo período da assistência no âmbito hospitalar deixou marcas para atuação dos profissionais e para os usuários. Ambos apresentam dificuldades em considerar essa dimensão do cuidado, embora a $\mathrm{PNAB}^{2}$ preconize o cuidado integral ao usuário e à família.

Mecanismos de controle e também de punição foram bastante expressivos na fala dos profissionais. Esses mostram dificuldade em lidar com o usuário que surge nas unidades básicas de saúde, bastante diferente dos daqueles dos hospitais, onde o sujeito se encontra subjugado às regras e ao cotidiano dessa instituição. Os usuários da ESF têm mais possibilidade de escolhas, pode priorizar diferentes necessidades de sua vida. É necessário considerar que o 
cuidado em saúde é apenas mais uma entre tantas outras necessidades que surgem. É como se a Atenção Primária concorresse com a vida, de certo modo.

Os motivos apresentados pelos profissionais e usuários para as faltas às consultas programadas apontam para uma importante questão: $\mathrm{o}$ desconhecimento das diversas realidades, que pode estar refletindo no desejo de punição dos profissionais aos usuários faltosos. Foucaultii quando descreveu as características de uma sociedade disciplinar, elencou diversos mecanismos punitivos com o objetivo de produzir corpos dóceis, disciplinados e obedientes. Deste modo, para os profissionais, o usuário deve se submeter a suas condutas, ele deve ser obediente e caso não obedeça, deve ser punido; só assim ele compreenderá o prejuízo que sua falta provoca ao serviço e a si mesmo.

Por outro lado, a equipe se sente frustrada e desvalorizada, pois, muitas vezes, compreende a falta dos usuários como uma atitude de indiferença. Esse sentimento também pode reforçar mecanismos de punição, como uma reação à hostilidade sentida.

Por fim, a existência de barreiras econômicas no acesso a um sistema de saúde público e universal pode parecer, a princípio, um contrassenso. Entretanto, os achados desta pesquisa mostraram que aspectos econômicos influenciaram às faltas dos usuários aos serviços de saúde.

A dimensão econômica da acessibilidade se mostrou relacionada à dimensão geográfica. $\mathrm{Na}$ análise de Donabedian ${ }^{5}$, o custo da viagem é um dos aspectos da dimensão geográfica. Já para os autores Penchansky e Thomas ${ }^{3}$, o custo com os meios de transporte está incluído na dimensão acessibilidade - tomado por estes autores como uma dimensão do acesso (Accessibility).

Para Aday e Andersen ${ }^{\mathrm{iii}}$ as distintas características do sistema de saúde e da população podem determinar a possibilidade de ingressar no serviço de saúde. Além disso, o acesso em si não consiste apenas na disponibilidade dos serviços e recursos, mas sim na possibilidade dos serviços serem utilizados por quem os necessite.

Os resultados desta pesquisa demonstraram que o gasto de tempo demandado para a obtenção da consulta na unidade de saúde pode se configurar como uma das barreiras da acessibilidade. É importante considerar que na sociedade atual o tempo tem uma representatividade financeira, o que justifica a expressão "tempo é dinheiro", reproduzindo a concepção capitalista de que o tempo nunca pode ser ocioso, ou seja, improdutivo.

Outro aspecto a ser incluído na discussão da dimensão econômica é a descrição de capacidade de compra (Affordability), trazida por Penchansky e Thomas ${ }^{3}$. Esta capacidade de compra pode se configurar em gastos diretos ou indiretos na obtenção dos cuidados em saúde. Deste modo, considerou-se como barreiras de acessibilidade importantes o consumo de recursos e os prejuízos financeiros decorrentes da perda de dias de trabalho. Esta realidade faz com que os usuários passem a se relacionar com o serviço apenas na ocorrência de um agravo à saúde.

É importante também considerar os gastos que estes usuários têm quando são referenciados para outros serviços, como transporte, alimentação e tempo, já que esta prática migratória é uma realidade dos usuários para a busca e obtenção de atendimento especializado e exames diagnósticos mais sofisticados, uma vez que a ABS necessita do apoio dos serviços da rede de saúde.

Para Travassos, as desigualdades em saúde refletem, dominantemente, as desigualdades sociais e envolve outras questões complexas, como, por exemplo, a questão da capacidade de financiamento do sistema de saúde local e o seu desenho de modelo assistencial.

\section{Consideratōes Finais}

Frente aos resultados deste estudo, observou-se que a forma como o serviço está organizado, a falta de profissionais e a consequente sobrecarga de trabalho dos remanescentes interferem no fenômeno das faltas dos usuários às consultas programadas. Formas mais participativa de gestão do serviço e definições de estratégias para fixação dos profissionais na atenção básica poderão contribuir para a superação das barreiras de acessibilidade impostas aos usuários.

Os problemas de acessibilidade podem decorrer da combinação entre a ausência de espaços de escuta com a rigidez programática na organização da agenda dos profissionais da equipe. O espaço de diálogo gestão disponível para os usuários da unidade é a reunião mensal 
do colegiado gestor que conta com um representante da associação de moradores na composição, ou seja, ainda pouco para a institucionalização de mecanismos que permitem a participação e controle social.

Percebeu-se também que a coexistência de duas estratégias de APS, com portas de entrada distintas em uma mesma unidade de saúde, pode impor desafios à legitimação do modelo de ESF, podendo confundir trabalhadores e usuários, como no caso da unidade W.

Os profissionais de saúde demonstraram preocupação com as faltas dos usuários às consultas, porém esse fenômeno não se tornou um dispositivo-analisador do cuidado prestado ou do modo como organizam o serviço. As faltas dos usuários às consultas, segundo os profissionais, foram atribuídas às dificuldades de ordem pessoal ou desinteresse dos usuários.

É importante o apoio para o fortalecimento e qualificação dos espaços de discussão e reflexão sobre o trabalho entre os profissionais, para construção de maneiras mais eficientes e, ao mesmo tempo, agradáveis de produzi-lo. A reflexão a respeito do processo de trabalho também deve considerar as necessidades de saúde dos usuários. Nesse sentido, o apoio matricial é uma ferramenta fundamental.

Para se constituir de fato, a ESF necessita mais do que princípios e diretrizes, é preciso mudança na produção de subjetividades. Não importa o nome que se dê ao modelo assistencial, o modo como os profissionais de posicionam frente ao usuário é o que dirá em que base se sustenta a assistência prestada.

Cabe destacar que ESF propõe a ampliação do olhar dos profissionais para os usuários, considerando o sujeito, de modo singular, inserido num contexto social e familiar, carregado de afetos, desejos, aspirações e dificuldades, ou seja, o usuário não se resume a seu corpo biológico, nem tão pouco, o cuidado em saúde deve se resumir a ele.

As superações das barreiras à acessibilidade enfrentadas pelos usuários apontam para necessidade de intervenções que extrapolam o setor da saúde. Práticas intersetoriais, além de políticas econômicas, de mobilidade urbana, habitação, saneamento básico, segurança pública e educação são exemplos de ações que podem contribuir para melhoria no acesso aos serviços de saúde.

É importante apontar algumas limitações dessa pesquisa, com vista a possibilitar o desenvolvimento de estudos futuros que contemplem alguns aspectos não abordados aqui, em virtude da limitação dos instrumentos e técnicas escolhidas. As quatro dimensões de acessibilidade analisadas nessa pesquisa geográfica, organizacional, sociocultural e econômica - são bastante complexas e alguns aspectos não foram possíveis de serem apreendidos.

Na dimensão geográfica, não foi possível concluir o quanto o tempo gasto pelos usuários no deslocamento até a unidade de saúde se configurou como barreira de acessibilidade para os usuários entrevistados, pois dada a precariedade das condições do território em que vivem, as dificuldades podem estar naturalizadas.

Já a análise da dimensão organizacional não permitiu compreender algumas condutas da equipe estudada, o que pode incorrer em interpretações equivocadas. Exemplo disso é o desconhecimento dos pesquisadores sobre os motivos que levam os profissionais a estruturarem suas agendas com tamanha rigidez programática sobre as explicações a respeito da estruturação das agendas médica e de enfermagem.

O nível de conhecimento sobre a oferta de serviços de saúde, crenças a respeito dos diagnósticos e intervenções dele decorrentes, são alguns exemplos da dimensão sociocultural que não puderam ser abordados. Alguns aspectos dessa dimensão necessitam de outras técnicas de coleta de dados mais aprofundadas do que a realização de uma única entrevista.

Em relação à dimensão econômica, não foi possível conhecer a renda familiar dos entrevistados devido à estruturação do roteiro para as entrevistas, porém este indicador tem importância central para análise dessa dimensão.

O fato de existir pouca produção bibliográfica sobre a situação problema investigada e por esta ter repercussões importantes no funcionamento dos serviços de saúde, recomenda-se o desenvolvimento de novos estudos para aprofundar as questões aqui discutidas e contribuir para atenuação do fenômeno das faltas.

\section{Referêneias}

1. Brasil. Ministério da Saúde. Secretaria de Assistência à Saúde. Coordenação de Saúde da Comunidade. Saúde 
da Família: uma estratégia para a reorientação do modelo assistencial. Brasília. Ministério da Saúde, 1997, p. 36.

2. Brasil. Ministério da Saúde. Secretaria de Atenção à Saúde. Departamento de Atenção Básica, Portaria $\mathrm{n}^{\circ} .2488$ de 21 de Outubro de 2011. Política Nacional de Atenção Básica. Brasília: Ministério da Saúde, 2011.

3. Penchansky RDBA, Thomas W. The Concept of Access: Definition and Relationship to Consumer Satisfaction. Medical Care, Vol. 19, No. 2 (Feb., 1981), pp. 127-140.

4. Travassos C, Martins M. Uma Revisão sobre OS Conceitos de Acesso e utilização de Serviços de Saúde. Cad. Saúde Pública, Rio de Janeiro, 2004.

5. Donabedian A. Aspects of medical care administration. Cambridge, Mass.: Havard University Press, 1973.

6. Fekete MC. Estudo da acessibilidade na avaliação dos serviços de saúde. In: Ministério da Saúde, organizador. Desenvolvimento gerencial de unidades básicas de saúde no distrito sanitário. Projeto Gerus. Brasília: Ministério da Saúde/Organização Pan-americana de Saúde; 1995. p.177-84.

7. Prefeitura Municipal de Biguaçu. Disponível em: $<$ https://www.bigua.sc.gov.br/blog/excesso-de-faltasas-consultas-e-exames-prejudica-saude-municipal/>. Acessado em: 31 de Agosto de 2012.

8. Prefeitura Municipal de Santos. Disponível em: <http://www.santos.sp.gov.br/nsantos/index.php/not icias/at-40-faltam-aos-exames-e-consultas-na-redepblica>. Acessado em: 31 de Agosto de 2012.

9. Jornal da Cidade. Disponível em: <http://jornalcidade.uol.com.br/rioclaro/dia-adia/saude/83860--Cerca-de-30dos-pacientes-faltam-asconsultas-agendadas-sem-avisar->. Acessado em: 31 de Agosto de 2012.

10. Yin RK. Estudo de caso: Planejamento e métodos. $4^{a}$. Ed., Porto alegre: Bookman, 2010.

11. Minayo MCS. O Desafio do Conhecimento: pesquisa qualitativa em saúde. $8^{\text {a }}$ ed. SP: HUCITEC/ RJ: ABRASCO, 2010.

12. Marconi MA, Lakatos EM. Fundamentos da Metodologia Científica. $5^{\mathrm{a}}$ ed. SP: Editora Atlas, 2003.

13. Pimentel, A. O método da análise documental: Seu uso numa pesquisa historiográfica. Cadernos de Pesquisa, n.114, p. 179-195, novembro/2001.

14. Franco, TB. O uso do fluxograma descritor e projetos terapêuticos para análise de serviços de saúde, em apoio ao planejamento: o caso de luz (MG). In: Merhyet al. O trabalho em saúde: olhando e experienciando o SUS no cotidiano. São Paulo: Hucitec, 2007.

15. Bardin L. Análise de conteúdo. $1^{\mathrm{a}}$ reimp. da $1^{\mathrm{a}}$ ed. São Paulo: Edições 70, 2011.

16. Instituto Brasileiro de Geografia e Estatística (IBGE). Censo demográfico: Aglomerados subnormais. Rio de Janeiro, 2010. Disponível em >http://censo2010.ibge.gov.br/resultados. Acessado em: 10/03/2013.

17. Martins K. Expansão urbana desordenada e aumento dos riscos ambientais à saúde: o caso brasileiro. (Monografia). Universidade de Brasília. Planaltina, DF, 2012. Disponível em: <www.bdm.bce.unb.br/bitstream/10483/4135/1/2012> Acesso em: 23 de setembro de 2013.

18. Cohn et al. Acesso em discussão: viés da racionalidade e o viés da carência. In: Cohn et al. A saúde como direito e como serviço. $4^{\text {a }}$ ed. São Paulo. Cortez, 2006.
19. Ceccim RB, Feuerwerker, LCM. O Quadrilátero da Formação para a Área da Saúde: Ensino, Gestão, Atenção e Controle Social. Physis: Rev. Saúde Coletiva, Rio de Janeiro, v.14, n.1, p.41- 65, 2004.

20. Merhy EE. Um ensaio sobre o médico e suas valises tecnológicas: contribuições para compreender as reestruturações produtivas do setor saúde (mimeo). Campinas, 1999.

21. Foucault M. Vigiar e Punir: Nascimento da prisão. Trad. Raquel Ramalhete. Petrópolis: Vozes, 1987.

22. Aday L, Andersen R. A framework for the study of access to medical care. Health Serv Res, 1974; 9:208-20.

23. Travassos C, et al. Desigualdades geográficas e sociais na utilização de serviços de saúde no Brasil. Cad. Saúde Pública, Rio de Janeiro, v.5, n. 1, p. 133-149. 2000. 